\title{
Medidas Emergenciais para a População em Situação de Rua: enfrentamento da PANDEMIA E SEUS EFEITOS ${ }^{1}$
}

Tatiana Dias Silva²

Marco Natalino ${ }^{3}$

Marina Brito Pinheiro ${ }^{4}$

\section{INTRODUÇÃO}

A partir de março de 2020, quando da eclosão e intensificação dos efeitos da pandemia da Covid-19 no Brasil, foi possível identificar iniciativas governamentais para assistir aos grupos mais vulneráveis diante das necessidades de subsistência, manutenção da saúde, isolamento e distanciamento social, como transferência direta de renda, isenção de tarifas e distribuição de alimentos, itens de higiene e equipamentos de proteçấo individual. Também foram notificadas açôes, ainda mais incipientes, de isolamento de idosos e outras pessoas de grupos de risco - como moradores de residências adensadas em abrigos provisórios (Calmon, 2020; Observatório das Desigualdades, 2020).

Diante de todas essas emergências, a atenção à população em situação de rua (PSR) consegue congregar toda a sorte de dramas e demandas, não raro subestimados e naturalizados nas grandes cidades. A necessidade de isolamento social e higiene para aqueles que não têm sequer moradia (ou que dispóem de residências provisórias coletivas) e a limitaçáo repentina e severa dos já precários meios de sobrevivência (doaçôes e pequenos serviços) aprofundam o abismo social que esse grupo vivencia.

Este texto vem identificar as principais iniciativas adotadas pelos gestores municipais voltadas à PSR no contexto da crise sanitária e de seus efeitos. Busca-se, aqui, sintetizar e atualizar os achados de pesquisa relatados na Nota Técnica no 74, População em Situação de Rua em Tempos de Pandemia: um levantamento de medidas municipais emergenciais (Silva, Natalino e Pinheiro, 2020), incorporando aspectos não explorados neste primeiro documento e, por sua vez, apenas referenciando outros itens que foram melhor abordados inicialmente. ${ }^{5}$

\section{PSR E POLÍTICAS PÚBLICAS}

Em fevereiro de 2020, mais de 146 mil pessoas declararam estar em situação de rua no Cadastro Único para Programas Sociais do Governo Federal (Cadastro Único) (Brasil, 2020). Estudo realizado por Natalino (2020), a partir de dados em painel do Cadastro Único e do Censo do Sistema Único de Assistência Social (Censo SUAS), estimou a existência de cerca de 221 mil pessoas em situação de rua no Brasil no momento da eclosão da pandemia, estando elas concentradas em municípios de grande porte e em metrópoles, especialmente no Sudeste (56\%) e Nordeste (17,2\%). Foi reportado crescimento expressivo dessa população entre setembro de 2012 e março de 2020 (140\%), o que deixa patente como o quadro de vulnerabilidade já vinha se agravando nos últimos anos.

1. DOI: http://dx.doi.org/10.38116/bapi25art9

2. Técnica de planejamento e pesquisa na Diretoria de Estudos e Políticas do Estado, das Instituições e da Democracia (Diest) do Ipea.

3. Especialista em políticas públicas e gestão governamental na Diretoria de Estudos e Políticas Sociais (Disoc) do Ipea.

4. Pesquisadora do Programa de Pesquisa para o Desenvolvimento Nacional (PNPD) na Disoc/lpea.

5. Este texto conta, inclusive, com trechos extraídos da referida Nota Técnica, elaborada pelos mesmos autores deste artigo. 
Segundo dados do I Censo e Pesquisa Nacional sobre a População em Situação de Rua, englobando 71 cidades e 32 mil pessoas acima de 18 anos, essa populaçáo é composta, em sua maioria, por homens (82\%), negros (67\%) e jovens (43,21\% dos homens e 52,23\% das mulheres até 35 anos), com baixa escolaridade (17,1\% são analfabetos). São pessoas que estão na rua ou em albergues há bastante tempo ( $48,4 \%$ há mais de 2 anos), fato que atribuem prioritariamente a problemas com álcool e/ou outras drogas (35,5\%), desemprego (29,8\%) e desavenças familiares $(29,1 \%)$. Seus vínculos familiares estão rompidos ou bastante fragilizados $(51,9 \%$ têm parentes na cidade em que se encontram, mas 38,9\% não mantêm contato). $\mathrm{O}$ rompimento de laços sociais, a vulnerabilidade econômica e a saúde mental se somam na composição do fenômeno. A maior parte trabalha (70,9\% exercem alguma atividade remunerada e 58,9\% afirmam ter alguma profissão). São ainda pessoas que apresentam enfermidades em porcentagem superior à população geral de baixa renda (30\% têm algum problema de saúde) e 24,8\% não possuíam documentos (Brasil, 2009). Com efeito, o censo mostrava cenário de população de maioria masculina, negra, em situação cristalizada de rua, de baixa escolaridade e alijada de amparo governamental básico. Além disso, os dados do último censo da cidade de São Paulo, de 2019, corroboram esses achados. Nesta pesquisa, foram identificadas 24.344 pessoas em situação de rua. ${ }^{6}$ Em São Paulo, desde 2000, verificou-se um aumento de $179 \%$ nesse contingente (Qualitest Inteligência em Pesquisa, 2019).

$\mathrm{O}$ avanço da pandemia ocorre em um cenário de ampliação da PSR, apresentando enorme desafio adicional para as políticas públicas. Além dos riscos inerentes à doença, que tem como medidas sanitárias prioritárias o isolamento, o distanciamento social e a higiene - aspectos distantes das condiçôes dispostas para a realidade desse grupo populacional -, a ausência de circulação social nas ruas impóe obstáculos para subsistência diária, dada a escassez das fontes de trabalho, renda e doaçóes (Qualitest Inteligência em Pesquisa, 2019). Embora o governo federal tenha aprovado auxílio emergencial a ser pago para parte das pessoas de baixa renda, a PSR enfrenta dificuldades adicionais - por vezes, intransponíveis (como ausência de qualquer documento) - para acessá-lo, bem como está exposta a outros tipos de riscos que nem o valor nem a natureza desse recurso são capazes de suprir (Qualitest Inteligência em Pesquisa, 2019).

A rede pública de atenção à PSR está basicamente articulada em torno de iniciativas governamentais no âmbito dos sistemas de saúde e da assistência social, em geral executadas pelos municípios. No âmbito da saúde, tem-se como serviço específico o Consultório na Rua (CR), ${ }^{7}$ estratégia constituída por equipes multiprofissionais que fazem atendimento fixo ou móvel, oferecendo atenção integral à saúde. Em 2018, havia 152 equipes em 105 municípios (Brasil, 2019), aquém do contingente elegível de 307 equipes em 262 municípios, conforme destacam Medeiros e Cavalcante $\left(2018\right.$, p. 756). ${ }^{8}$ Embora presente em quase todo o território nacional, verifica-se que a difusão dessa estratégia ainda é limitada - apenas cinco estados contam com dez ou mais equipes de CR. Ademais, o seu crescimento também é limitado ao longo dos anos (passando de 152 equipes em 2018 para 164 em 2020), a despeito de aumento do contingente da PSR (Silva, Natalino e Pinheiro, 2020, p. 10).

6. Nota-se que o número está provavelmente subestimado, pois a pesquisa foi realizada em conjunto com atividade de abordagem policial. Os dados em painel do Censo SUAS, bem como de uso de serviços assistenciais pela PSR, sugerem número bastante superior a 24 mil pessoas. Ademais, a percepção de especialistas entrevistados é de que essa população se tornou ainda maior desde o início da pandemia, particularmente na região do centro da cidade.

7. Instituído por meio da Portaria no 2.488/2011 e da Portaria no 122/2011.

8. Entre os fatores apontados por municípios como principais razões para não implantação das equipes de CR estão o financiamento considerado não adequado por parte do governo federal e o alto ônus para implantação da estratégia, entre outros (Medeiros e Cavalcante, 2018). 
Tal como na área da saúde, além dos serviços mais amplos da assistência social, há serviços específicos desenvolvidos para esse público. Destaca-se o Serviço Especializado para Pessoas em Situação de Rua (Centro Pop), de média complexidade, e aqueles de alta complexidade, como o Serviço de Acolhimento Institucional (para adultos e famílias) e o Serviço de Acolhimento em Repúblicas (para adultos em processo de saída das ruas). Assim como o CR, os serviços da assistência social, voltados para a PSR, apresentam restrita implementação e abrangência. Tomando-se apenas o exemplo do Centro Pop, segundo dados do Censo SUAS de 2019, o país contava somente com 228 unidades desse equipamento naquele ano, presentes em duzentos municípios e concentradas na regiáo Sudeste (46,5\%). Em 2017, análise feita pelo Ministério da Cidadania mostrou que, dos municípios com mais de 100 mil habitantes e daqueles de regióes metropolitanas com 50 mil habitantes ou mais, 31,3\% não contavam com algum tipo de serviço voltado para a PSR. ${ }^{9}$ Os Centros de Referência Especializados de Assistência Social (CREAS) - que também atuam no atendimento da PSR por meio de serviços gerais e específicos, ${ }^{10}$ e cuja existência é condição para que os municípios sejam elegíveis ao cofinanciamento federal para os Centros Pop - apresentam deficit de 242 unidades em todo o país, principalmente no Sudeste, onde ainda faltariam 131 unidades para garantir a oferta adequada segundo as orientaçóes técnicas emitidas pelo entáo Ministério do Desenvolvimento Social e Combate à Fome (Brasil, 2011).

Se o acesso da PSR a serviços de saúde e assistência social já é limitado em sua abrangência, além de encontrar problemas tanto na rede universal como nas iniciativas específicas, ${ }^{11}$ no contexto da atual crise esses obstáculos são agravados, a exemplo da redução da oferta de serviços públicos ou migração para atendimento remoto. Diante desse cenário, muitos gestores públicos - além da sociedade civil organizada - têm procurado responder a essa crise com açóes específicas para esta populaçáo.

\section{MEDIDAS EMERGENCIAIS PARA A PSR}

Para realizar essa investigação, foram consultados: i) sítios eletrônicos das prefeituras das capitais do Nordeste e Sudeste, ${ }^{12}$ notadamente relativos a secretarias de assistência social ou à pandemia, entre março e abril de 2020; ii) artigos e notícias sobre o tema, particularmente nas capitais indicadas anteriormente; e iii) atores estratégicos, como gestores governamentais, representantes da Defensoria Pública da União e de defensoria estadual, do Movimento Nacional da População de Rua (MNPR) e outras organizaçóes da sociedade civil, além de pesquisadores de diversas formaçóes atuantes em Salvador, Natal, Fortaleza, Rio de Janeiro, São Paulo e Brasília. Ao total, foram realizadas catorze entrevistas.

O levantamento não pretendia ser exaustivo, tampouco se almejou avaliar a implementação das açôes identificadas ou o quadro anterior das medidas municipais para a PSR, apesar da importância dessas informaçóes. Antes, o foco foi analisar quais tipos de iniciativas foram desenvolvidas em caráter emergencial, e como se somam ou inovam em relação ao quadro atual de serviços governamentais disponibilizados para essa população.

9. Segundo cálculos realizados para aferição das metas do Pacto de Aprimoramento da Gestão Municipal do SUAS. Disponível em: <https:// bit.ly/3cQdNDw>.

10. Note-se que, na ausência de um Centro Pop no território, o serviço especializado para pessoas em situação de rua pode e deve ser realizado pelas equipes dos CREAS.

11. 0 acesso desses indivíduos não raro é limitado por fatores como preconceito e exigências inadequadas (Carvalho, 2013; Miranda, 2017).

12. Essas regiões concentram mais de $70 \%$ da PSR, segundo Natalino (2020). 
As entrevistas com atores estratégicos tiveram como objetivo tanto validar a análise empreendida como compartilhar sua percepçáo sobre a qualidade e suficiência das iniciativas emergenciais em curso e suas sugestôes para melhor enfrentamento da crise. A partir dessa análise, foi possível identificar um conjunto de iniciativas que se concentram na ampliação ou readequação dos serviços existentes no âmbito do SUAS e do SUS, além da implementação de medidas inovadoras. O quadro 1 procura sintetizar o levantamento realizado.

QUADRO 1

Medidas emergenciais de âmbito municipal para a PSR no contexto da pandemia

\begin{tabular}{|c|c|}
\hline Categoria & Iniciativas \\
\hline \multirow{6}{*}{ Acolhimento } & Disponibilização de novas Unidades de Acolhimento. \\
\hline & Criação de unidades emergenciais provisórias em espaços públicos ou privados. \\
\hline & Locação de vagas em hotéis. \\
\hline & Implantação de unidades específicas para doentes, suspeitos ou pessoas em grupo de risco da Covid-19. \\
\hline & Encaminhamento (voluntário ou não) a comunidades terapêuticas. \\
\hline & Ampliação da concessão de auxílio-moradia. \\
\hline \multirow{3}{*}{ Alimentação } & Ampliação do horário de atendimento dos restaurantes populares, em geral, com entrega de marmitas para evitar aglomeração. \\
\hline & Descentralização dos restaurantes populares, para evitar aglomeração. \\
\hline & Oferta de alimentação nos Centros de Atenção Psicossocial (CAPS). \\
\hline \multirow{5}{*}{ Orientação } & Criação de normativas municipais com orientações para atendimentos à PSR durante a pandemia. \\
\hline & Serviço Especializado em Abordagem Social: ampliação de equipes e/ou horário de funcionamento. \\
\hline & Atividades de orientação da PSR em vias públicas ou em ações em Centros Pop ou Unidades de Acolhimento. \\
\hline & Abordagem social acompanhada de profissionais de saúde. \\
\hline & Treinamento para o voluntariado. \\
\hline \multirow{3}{*}{ Higiene } & Fornecimento de kits de higiene em equipamentos e em vias públicas. Algumas iniciativas articulam recursos públicos com doações privadas. \\
\hline & Higienização intensificada e especializada em Unidades de Acolhimento. \\
\hline & Instalação de equipamentos em vias públicas para mitigar as limitações de acesso à higiene, com pias, lavanderias e banheiros públicos. \\
\hline \multirow{4}{*}{ Saúde } & Intensificação da atuação e ampliação das equipes de CR e concentração das suas atividades para combate à Covid-19. \\
\hline & Triagem médica em abrigos: avaliação quanto a sintomas e encaminhamento para centro de testagem, quando necessário. \\
\hline & Direcionamento de vacinação contra a gripe pelas equipes de CR ou antecipação de campanha. \\
\hline & Visitas diárias itinerantes das equipes de Centros de Atenção Psicossocial Álcool e outras Drogas (CAPSad) para abordagem da PSR. \\
\hline \multirow{2}{*}{ Serviço } & Criação de equipamentos emergenciais para atendimento multiprofissional. \\
\hline & Criação de espaços de convivência emergencial, com concentração de serviços como alimentação e orientação. \\
\hline
\end{tabular}

Elaboração dos autores.

Obs.: Para ter acesso às notícias consultadas para a maioria das ações, ver Silva, Natalino e Pinheiro (2020).

Cabe destacar que o quadro 1 procura organizar as iniciativas a partir das categorias principais atribuídas a cada medida, ainda que não estejam desvinculadas entre si. Uma ação de abrigamento, em geral, envolve praticamente a maioria das outras categorias.

Entre as treze capitais inicialmente analisadas, as ações mais reportadas foram abrigamento (13), higiene (9) e alimentação (8). Conquanto medidas como criação de centros emergenciais de serviço (2) e atividades específicas de orientação (6) tenham sido menos frequentes, não raro este tipo de oferta está vinculado, em maior ou menor escala, a outros serviços, como abrigamento. Nesse sentido, a maior ausência foi de medidas específicas de saúde (identificadas notícias acerca do assunto em apenas seis capitais, entre as analisadas). Também estiveram pouco presentes, nas 
notícias veiculadas, medidas voltadas às pessoas com uso problemático de álcool e outras drogas e transtornos mentais.

Entre os principais limitadores diante das medidas emergenciais, relatam-se a dificuldade de testagem da PSR, a insuficiência das vagas de abrigamento e os obstáculos para inclusão em programas de transferências de renda, especialmente vinculadas ao acesso à informação, documentação e tecnologia. Também foi pontuada a necessidade de buscar os "mais vulneráveis entre os vulneráveis", aí incluídas as pessoas com transtornos mentais ou que vivem em situação de rua fora dos grandes centros e, por consequência, com menos acesso aos serviços públicos.

Entre as sugestôes para o poder público, os entrevistados citaram a ampliação/manutenção do diálogo social com as representaçóes do movimento social bem como a manutençáo das medidas emergenciais de abrigamento e alimentação. A crise é apontada como uma possibilidade, diante dessa tragédia de origem sanitária, de humanizar a rua. A implementação dessas medidas nesse momento mostra a viabilidade do aprimoramento e do aumento da oferta de políticas para essa populaçáo. Considerando-se o prolongamento da crise mesmo depois do auge da emergência sanitária, outra recomendaçáo é que o poder público fortaleça o sistema de assistência social, com vistas a prevenir que um contingente maior de pessoas venha a ficar desprotegida e venha a somar-se à atual PSR. Defende-se também que se busque fortalecer a articulação entre as políticas e entre estas e as ofertas realizadas pela sociedade civil.

Em relação ao abrigamento, chama-se atençáo para o fato de que a rede hoteleira, atualmente operando com capacidade ociosa, pode ser uma soluçáo adequada em diversos municípios, desde que seja ofertado treinamento adequado a seus profissionais e que sejam estabelecidas regras de convivência com alguma flexibilidade, para não afastar aqueles que se deveria proteger. A questão da liberdade de movimento segue sendo valor fortemente arraigado entre essa populaçáo, e qualquer iniciativa de abrigamento, para se fazer efetiva, deve considerá-la. Nesse quesito, a internação em comunidades terapêuticas tem sido apontada como risco potencial de violaçáo dos direitos humanos. Embora isso dependa da forma de prestação do serviço e do modo de encaminhamento do cidadáo (Santos, 2018), ressalta-se que muitas dessas comunidades não são suficientemente abertas às instituiçóes locais de assistência social e saúde (Pires, 2018). Ainda, na medida em que dificultam a manutenção dos vínculos sociais de seus internos por meio do bloqueio de visitas e de contatos digitais, geram inadaptação ao mundo civil fora de seus muros e, amiúde, reincidência (Natalino, 2018).

O abrigamento de pessoas acostumadas ao espaço da rua em um momento de pandemia envolve a oferta de ambientes com mínimo de conforto e espaçamento adequado entre os leitos. Foi reportado por especialistas que, na maioria das grandes cidades, parte da recusa em deixar a rua nesse momento está, para além da incapacidade da rede de acolhimento instalada de dar conta da demanda crescente, na oferta de acolhimento institucional em condições aquém das desejáveis, gerando insegurança por parte da PSR. Nesse tocante, é mais eficaz, em alguns casos, adaptar espaços públicos como escolas, que contam com salas separadas e cozinha, do que construir novas estruturas provisórias para atender essa população.

Além disso, especialistas e gestores públicos federais e municipais têm defendido a ampliação dos recursos destinados ao auxílio-moradia e sua combinação com serviços assistenciais e de saúde, educação e de intermediação da mão de obra por meio da metodologia Moradia Primeiro 
(Housing First), ${ }^{13}$ que se encontra em fase de teste em alguns municípios. Os resultados de estudos quase-experimentais dessa combinação particular de políticas em um rol de oportunidades de inclusão e redução da vulnerabilidade social da PSR indicam ser ela mais eficaz e menos custosa que as alternativas sem articulação institucional, particularmente em casos mais graves de saúde (Macnaughton et al., 2015; Busch-Geertsema, 2014).

\section{CONSIDERAÇÕES FINAIS}

O levantamento realizado mostra amplo rol de açôes anunciadas pelos municípios. Essas medidas não foram homogêneas em sua distribuição, oferta, qualidade, especificidade ou mesmo em sua temporalidade, aspecto fundamental para reduzir os impactos de uma pandemia. De fato, a descoordenação de ações revela como nosso pacto federativo ainda não se apropriou da temática da PSR para o devido balanceamento das corresponsabilidades. Assim, a difusão de boas práticas se faz pouco célere. Tal como manifestado pelos entrevistados, cabe esperar que este esforço, voltado a público tão vulnerável, não se dissipe com o desejável fim da pandemia. Uma esperança compartilhada é a de que estas açóes, que permitiram promover algum nível de proteção a essa população (a despeito dos limites apontados), possam ser mantidas e aperfeiçoadas, notadamente na forma de mais vagas para abrigamento, distribuição de alimentação e oferta de equipamentos públicos de higiene. ${ }^{14}$ Ademais, espera-se que a implementação de medidas mais definitivas para a PSR possa ser alçada à agenda de atenção prioritária dos governos. Nesse sentido, a implementação de políticas de habitação e cuidado, como nos moldes do modelo Moradia Primeiro, poderia ser conduzida em larga escala, garantindo a essa população, a partir da moradia, acesso a serviços públicos, educação e possibilidades efetivas de superação da situação de rua (Natalino e Pinheiro, 2020).

Por fim, cabe destacar a preocupação com os efeitos que a pandemia pode causar em termos do aumento do contingente da PSR. Para enfrentar esse cenário, além de ações emergenciais, o fortalecimento do sistema de proteção social se impóe como meio de estabelecer estratégias para alterar as condiçóes de vida das pessoas atualmente em situação de rua, bem como prevenir a ampliaçáo desse contingente. Contudo, essas expectativas passam pelo financiamento dos serviços como elemento fundamental.

A política de assistência social, que ocupa papel central no arcabouço de proteção social da PSR, tem lidado nos últimos anos com sucessivas reduçóes no financiamento federal dos seus serviços. No caso da proteção social especial, houve redução de R \$ 637 milhões (em 2019) para R \$ 518 milhóes no orçamento em 2020, sendo que o uso de mais de 60\% desse valor depende da aprovação de legislação específica no Congresso Nacional, não tendo, portanto, a garantia de liberaçáo. Cabe lembrar, no entanto, que durante a pandemia o Ministério da Cidadania distribuiu recursos extraordinários para estados e municípios no montante de mais de $\mathrm{R} \$ 570$ milhóes (até agosto de 2020) para gastos com açóes socioassistenciais de enfrentamento à Covid-19. O repasse teve como ênfase a proteção da PSR no contexto da pandemia. Esse financiamento, entretanto, foi realizado em um contexto de ausência de recursos ordinários usualmente transferidos para os serviços ofertados. Dessa maneira, apesar de o governo federal ter enviado recursos extras aos estados e municípios, o fez

13. Iniciativa voltada a pessoas em situação de rua, implementada em diversos países, que consiste no acesso imediato à moradia individual, com apoio de serviços multiprofissionais. Segundo o Ministério da Mulher, da Família e dos Direitos Humanos (MMFDH), atualmente existem quatro projetos-piloto no país sob sua coordenação (Brasil, 2020).

14. Reações a possibilidades de descontinuidades, no entanto, já podem ser notadas, como pode ser conferido, por exemplo, em Justiça... (2020). 
na ausência de recursos que normalmente eram enviados, sendo insuficientes para lidar com novas e complexas demandas surgidas ao longo da pandemia (Paiva et al., 2020; Pinheiro et al., 2020).

Outros aspectos igualmente essenciais, como a articulação federativa e a atenção aos trabalhadores envolvidos nos serviços, também devem ser objeto de atenção para continuidade e aprimoramento das açóes voltadas à PSR (Honorato e Oliveira, 2020), seja no contexto da crise sanitária, seja com vistas a um horizonte de emancipação e cidadania plena para esse público.

\section{REFERÊNCIAS}

BRASIL. Ministério do Desenvolvimento Social e Combate à Fome. I Censo e Pesquisa Nacional sobre a População em Situação de Rua: síntese dos resultados. In: Rua: aprendendo a contar - Pesquisa Nacional sobre População em Situação de Rua. Brasília: MDS, 2009.

Relatório de gestáo 2019. [s.l.]: Ministério da Saúde, 2019. Disponível em: <https:// bvsms.saude.gov.br/bvs/publicacoes/relatorio_gestao_ministerio_saude_2019.pdf>.

. Nota Técnica nº 5/2020/CGRIS/DEPEDH/SNPG/MMFDH. Orientaçóes gerais sobre atendimento e acolhimento emergencial à população em situação de rua no contexto da pandemia do Covid-19. Brasília: MMFDH, 2020.

BUSCH-GEERTSEMA, Volker. Housing First Europe: results of a European social experimentation project. European Journal of Homelessness, v. 8, n. 1, 2014.

CALMON, Tricia Viviane Lima. As condiçóes objetivas para o enfrentamento ao Covid-19: abismo social brasileiro, o racismo, e as perspectivas de desenvolvimento social como determinantes. Revista NAU Social, v. 11, n. 20, p. 131-136, 2020.

CARVALHO, Sandra Moreira Costa de. Pessoas em situação de rua: acesso universal às políticas sociais? Revista de Ensino, Educaçáo e Ciências Humanas, v. 14, n. 1, p. 57-64, 2013.

HONORATO, Bruno Eduardo Freitas; OLIVEIRA, Ana Carolina S. População em situação de rua e Covid-19. Revista de Administraçáo Pública, v. 54, n. 4, p. 1064-1078, 2020.

JUSTIÇA determina que governo e Prefeitura de Manaus mantenham abrigos para pessoas em situação de rua em Manaus. G1, 30 jul. 2020. Disponível em: <https://glo.bo/34RKdLW>.

MACNAUGHTON, Eric et al. Implementing Housing First across sites and over time: later fidelity and implementation evaluation of a pan-Canadian multi-site Housing First program for homeless people with mental illness. American Journal of Community Psychology, v. 55, n. 3/4, p. 279-291, 2015.

MEDEIROS, Cristiane Reis Soares; CAVALCANTE, Pedro. A implementação do programa de saúde específico para a população em situação de rua: Consultório na Rua - barreiras e facilitadores. Saúde e Sociedade, v. 27, n. 3, p. 754-768, 2018. Disponível em: <https://doi.org/10.1590/s0104$12902018170946>$.

MIRANDA, Fabiana Almeida. Direito à saúde para a população em situaçáo de rua de Salvador: Cartão SUS e Pop Rua. Salvador: [s.n.], 2017. 
MORAES, Rodrigo Fracalossi de. Medidas legais de incentivo ao distanciamento social: comparação das políticas de governos estaduais e prefeituras das capitais no Brasil. Brasília: Ipea, 2020. (Nota Técnica, n. 16).

NATALINO, Marco Antônio Carvalho. Isolamento, disciplina e destino social em comunidades terapêuticas. In: SANTOS, Maria Paula Gomes dos (Org.). Comunidades terapêuticas: temas para reflexão. Rio de Janeiro: Ipea, 2018. cap. 2.

Estimativa da população em situaçáo de rua no Brasil (setembro de 2012 a março de 2020). Brasília: Ipea, 2020. (Nota Técnica, n. 73).

NATALINO, Marco Antônio Carvalho; PINHEIRO, Marina Brito. Proteçáo social aos mais vulneráveis em contexto de pandemia: algumas limitaçóes práticas do auxílio emergencial e a adequação dos benefícios eventuais como instrumento complementar de política socioassistencial. Brasília: Ipea, 2020. (Nota Técnica, n. 67).

OBSERVATÓRIO DAS DESIGUALDADES. Sobre curvas e pirâmides: a geometria da desigualdade na pandemia. Boletim Observatório das Desigualdades, n. 9, p. 1-29, 2020. Disponível em: $<$ https://bit.ly/38V4rGY>.

PAIVA, Luís Henrique et al. Evitando a pandemia da pobreza: possibilidades para o Programa Bolsa Família e para o Cadastro Único em resposta à Covid-19. Brasília: Ipea, 2020. (Nota Técnica, n. 59).

PINHEIRO, Marina Brito et al. $\mathbf{O}$ financiamento federal dos serviços socioassistenciais no contexto da Covid-19. Brasília: Ipea, 2020. (Nota Técnica, n. 80).

PIRES, Roberto Rocha Coelho. Um campo organizacional de comunidades terapêuticas no Brasil? Dos processos de convergência e suas implicaçóes às clivagens emergentes. In: SANTOS, Maria Paula Gomes dos (Org.). Comunidades terapêuticas: temas para reflexão. Rio de Janeiro: Ipea, 2018. cap. 7.

QUALITEST INTELIGÊNCIA EM PESQUISA. Pesquisa censitária da população em situaçáo de rua: caracterização socioeconômica da população em situação de rua e relatório temático de identificação das necessidades desta população na cidade de São Paulo. São Paulo: Qualitest, 2019. SANTOS, Maria Paula Gomes dos (Org.). Comunidades terapêuticas: temas para reflexão. Rio de Janeiro: Ipea, 2018.

SILVA, Tatiana Dias; NATALINO, Marco; PINHEIRO, Marina Brito. População em situaçáo de rua em tempos de pandemia: um levantamento de medidas municipais emergenciais. Brasília: Ipea, 2020. (Nota Técnica, n. 74). 